\title{
ANTONIO ROALAS. UN PINTOR DEL PRIMER TERCIO DEL SIGLO XVII EN MADRID ${ }^{1}$
}

El conocimiento que actualmente se tiene sobre los pintores del barroco madrileño ha avanzado mucho desde que Angulo y Pérez Sánchez publicaran los dos volúmenes dedicados al primer y segundo tercio del siglo XvII. Posteriormente han ido viendo la luz estudios más pormenorizados, a veces en forma de exposiciones, que han clarificado aún más la importancia de los artistas que trabajaron en torno a la Corte de los llamados «los Austrias menores»; sin embargo, existen aún hoy un buen número de pintores sólo conocidos a través de contratos o inventarios de la época. La absoluta desinformación que tenemos de ellos, acrecentada por la inexistencia de obras firmadas, no permite a los historiadores dedicarles al menos un estudio parcial de su arte.

Por ello la aparición de cualquier obra firmada de estos pintores debe señalarse con un pequeño estudio, pues aunque necesariamente breve, sí permite configurar una idea más global de la pintura barroca madrileña de principios del xvil.

El Museo de Guadalajara ${ }^{2}$ conserva un San Jerónimo (Fig. 1) firmado en la zona inferior del lienzo (Fig. 2), justo debajo de los libros, por: DON ANTONIO ROALAS FEZID. Poco o nada sabemos de este pintor; Palomino no lo recoge en sus biografías de pintores, y mucho menos Lázaro Díaz del Valle o Ceán Bermúdez en su «Diccionario». Gracias a la labor de Mercedes Agulló y Cobo ${ }^{3}$ hemos podido recoger un testimonio que permite encuadrar al hasta ahora desconocido artista en el marco de la pintura madrileña del primer tercio del siglo XviI.

En el inventario de bienes del pintor Juan Andrés de Roble ${ }^{4}$, realizado el 12 de octubre de 1614, aparece como testigo Antonio Roalas. El documento, fechado como acabamos de ver en 1614, presupone que el artista pudo haber nacido al menos unos treinta años antes, alrededor de los últimos años de la década de 1580 o ya entrados los años de 1590. Se trata por tanto de un artista formado en el seno del «manierismo reformado» de corte escurialense, aunque su única obra conservada poco tiene que ver en realidad con ello.

El lienzo aparece por primera vez documentado en 1846 en la Comisión de Monumentos ${ }^{5}$ con el número de catálogo 325 , pero desgraciadamente de su procedencia no se indica más que su vinculación a los conventos desamortizados. En 1902 Carmelo Baquerizo ${ }^{6}$ lo recoge con el número 179 como San Gerónimo en actitud de recibir la inspiración del Espíritu Santo para escribir, colocado en la Antesala de la Presidencia del por entonces Palacio de la Diputación de Guadalajara. De ahí pasaría al actual Museo, ubicado en el Palacio del Infantado.

Una simple mirada al cuadro pone de manifiesto la inmediata vinculación de la obra con los modelos de Ribera ${ }^{7}$. Desde antiguo se ha venido pensando que las primeras obras del genial valenciano afincado en Nápoles comenzaron a llegar a la Corte en la década de 1620. Este dato, unido a la supuesta cronología del pintor, permitiría fechar el lienzo del Museo de Guadalajara en los años próximos a 1630.

\footnotetext{
'Quiero agradecer en primer lugar las indicaciones del Profesor Pérez Sánchez a la hora de redactar esta pequeña varia. ${ }^{2}$ El lienzo fue recientemente expuesto en la muestra Estampa Grabada y Cuadro. Una íntima relación. Estampa, Salón Internacional del Grabado y Ediciones de Arte Contemporáneo, Madrid, 6-10 noviembre de 2002. Rodríguez Rebollo, Ángel: «Estampa Grabada y Cuadro. Una íntima relación», Estampa 2002, pp. 50-53.

${ }^{3}$ Agulló y Cobo, M. Noticias sobre pintores madrileños de los siglos XVI y xVII, 1978, pp. 136 y ss.

${ }^{4}$ AHPM, Protocolo 4291, fols. 213-217.

${ }^{5}$ AHPGU, Comisión de Monumentos, caja 2, «Nomenclatura de los cuadros que existen en el Museo Provincial de esta capital clasificados en la forma precisada por la Sección $2^{a}$ de la Comisión Central».

${ }^{6}$ Baquerizo, Carmelo. Catálogo de Pintura, Escultura y Monedas existentes en el Museo establecido en el Palacio de la Excelentísima Diputación Provincial, Guadalajara, 1902, p. 36.

${ }^{7} \mathrm{La}$ influencia riberesca se indica ya en la Guía de la Sección de Bellas Artes del Museo de Guadalajara, Guadalajara, 1986, p. 26-27, no cat. 5 .
}

AEA, LXXVII, 2004, 305, pp. 75 a 97 

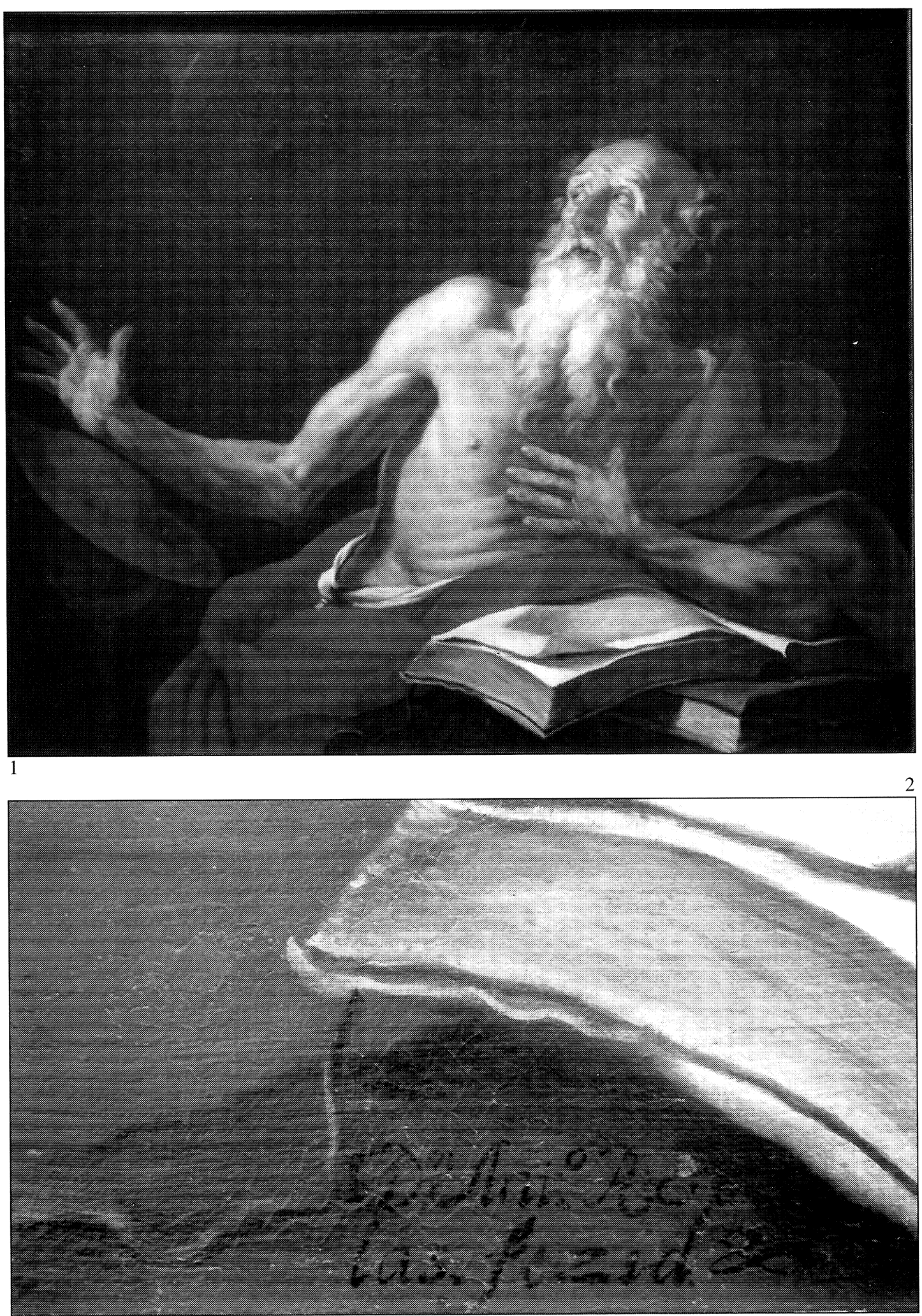

Fig. 1. Antonio de Roalas: San Jerónimo, hacia 1630. Museo de Guadalajara. Fig. 2. Antonio de Roalas: San Jerónimo. Firma. Museo de Guadalajara.

AEA, LXXVII, 2004, 305, pp. 75 a 97 


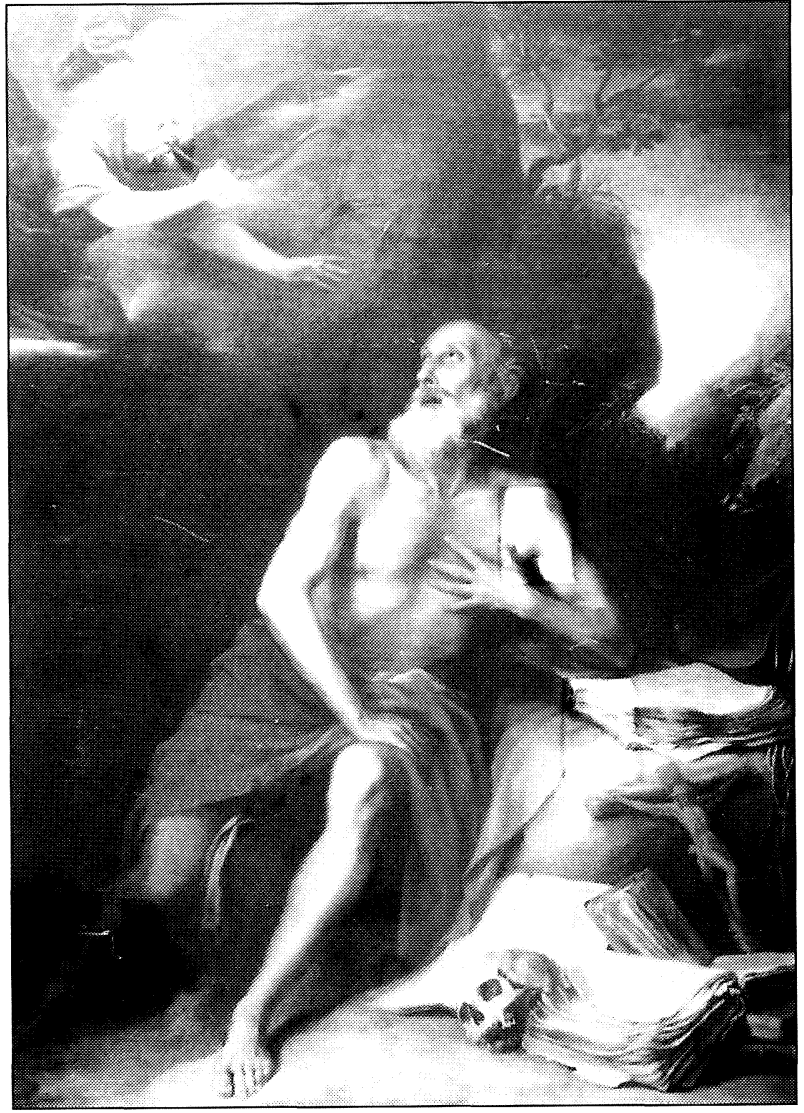

Fig. 3. Alonso Cano: San Jerónimo y el ángel, hacia 1658-1660. Mercado de arte.

Para realizar el San Jerónimo Roalas pudo manejar las conocidas estampas de San Jerónimo en el desierto de Ribera ${ }^{8}$, fechadas en 1621 y 1624 respectivamente. Sin embargo, la asimilación del tenebrismo caravaggesco del pintor napolitano que desprende el cuadro sólo se entiende desde el conocimiento directo de sus obras, máxime si pensamos que Roalas fue formado en el seco y anquilosado tardomanierismo de herencia escurialense.

Existe además otro factor que me hace pensar que efectivamente Roalas hubo de inspirarse directamente en alguna obra del napolitano. El gesto de la mano en el pecho no aparece en ninguna de las estampas de Ribera; además, éste, así como el gesto sorprendido de rostro, es virtualmente idéntico al que podemos ver en un San Jerónimo y el ángel de Alonso Cano (Fig. 3) subastado en 1991 en la galería Edmun Peel de Nueva York. Es de todos conocida la fascinación que Cano sintió por la obra de Ribera, algo que deja patente a lo largo de toda su producción artística.

De igual modo, hay que señalar de nuevo el paralelismo entre ambas obras en el detalle de la piedra sobre la que reposan los libros, aspecto directamente relacionado con los modelos riberescos. De otra parte, el gesto de la mano derecha y del rostro sorprendido del ermitaño ante la aparición, en el ángulo superior izquierdo, de la trompeta que anuncia las postrimerías, sí responden perfectamente a los modelos que aparecen en las citadas estampas.

En la actualidad no se conserva ninguna obra de Ribera con estas características, aunque esa no es razón para descartar que tanto Roalas como el propio Cano se sirvieron de alguna pieza que desgraciadamente no ha llegado hasta nosotros. Son tan evidentes los parentescos entre ambas obras que necesariamente la solución ha de pasar por el uso de un modelo común en ambos artistas.

Por último cabría señalar la relativa importancia que tendría esta obra inédita dentro del panorama de la pintura madrileña del primer tercio del XVII. En ella puede apreciarse la apuesta que hicieron los pintores barrocos madrileños hacia un decidido naturalismo. Además, es claro ejemplo de la rápida asimilación de los modelos de Ribera en la pintura barroca española en fechas tan tempranas como los años finales de la década de 1620 o los primeros de 1630.

No quisiera terminar este breve artículo sin antes hacer algunas precisiones sobre el lienzo de Alonso Cano que acabamos de citar. Por la novedad de los datos que se ofrecen merecen ser incluidas en este breve artículo.

\footnotetext{
${ }^{8}$ Junto a ello Pérez Sánchez («El Museo de Guadalajara», Archivo Español de Arte, XLVI, 1974, p. 94) lo recoge como curioso y de sorprendente calidad, advirtiendo también en el cierta evocación a Pereda.
} 
Debemos considerar el lienzo como una de las última obras realizadas por Cano en Madrid antes de su definitiva partida a Granada, muy estrechamente ligado por tanto a la Virgen de la Leche del Museo de Guadalajara. Sabemos que la obra permaneció en Madrid al menos hasta 1807, fecha en que fue grabado por Francisco de Paula Martí (1762-1827), académico numerario de la Real Academia de San Fernando. Titulado San Jerónimo Dr. y Fundador (Madrid, Biblioteca Nacional), en la estampa reza lo siguiente:

San Jerónimo Dr. y Fundador / Alonso Cano lo pintó; Franco de Paula Martí de la Real Academia de S. Fernando la dibujó y grabó en 1807.

Dedicada al Ilmo Señor D. Bernardo de Yriarte... su más humilde servidor Francisco de paula Martí.

Quizás sea el mismo San Jerónimo que le encargó Francisco Antonio de Quirós ${ }^{9}$. En 6 de Junio de 1651 Alonso Cano tomó en arriendo una casa suya a cuenta de realizar tres pinturas que representasen a Nuestra Señora de la Leche, San Jerónimo de cuerpo desnudo, y San Francisco en un país ${ }^{10}$ todas ellas de dos varas de altura por vara y media de ancho ${ }^{11}$. Debían ser copias o versiones de alguna otra ya realizada anteriormente de su mano, hecho que además certifica la afición de Cano por realizar varias versiones sobre algunas de sus composiciones más populares, condicionadas claro está a los encargos de los demandantes.

Parece ser que las obras no llegaron a ejecutarse, pues existe una copia de la escritura en 26 de junio de 1652, estando Cano ya en Granada y que debe responder, como muy bien ha señalado Valdovinos ${ }^{12}$, una reclamación ante el incumplimiento del contrato. Quizás tras su regreso a Madrid en 1657 pudo terminar estas obras, que dejaría inacabadas.

Ángel RodRíGuez ReBOLLo

\footnotetext{
${ }^{9}$ Cruz Valdovinos, J. M.: «Encargos y clientes de Alonso Cano en la Corte de Felipe IV», Alonso Cano. La modernidad del siglo de oro español. Madrid, 2002, pp. 87-88.

${ }^{10}$ Valdovinos (2002), p. 87-88.

"Es importante señalar la coincidencia entre las dimensiones del lienzo $(183 \times 132 \mathrm{~cm})$ y las dimensiones que se citan en el inventario de Francisco Antonio de Quirós (dos varas de altura por vara y media de ancho).

12 Valdovinos (2002), p. 88
} 